\title{
Vocabulary Learning Autonomy through Incorporation of English Songs: Indonesian EFL Students' Perspectives
}

\author{
IKA WAHYUNI LESTARI \\ English Language Education Department, Faculty of Language Education \\ Universitas Muhammadiyah Yogyakarta, Indonesia \\ ikawahyuni_11@umy.ac.id \\ NURI HARDIYANTI \\ English Language Education Department, Faculty of Language Education \\ Universitas Muhammadiyah Yogyakarta, Indonesia
}

\begin{abstract}
English songs have been widely used by learners as a medium to learn vocabulary. This qualitative study explored Indonesian students' experiences in using English songs as a medium to learn vocabulary autonomously outside in-class learning. Data were collected through in-depth interview to four second-year English Department students who reported using English songs to help them acquire vocabulary autonomously. The results of the interview showed that the participants preferred slow beat tempo of songs to obtain clear understanding on the words used in the songs. They also reported that the decision to use English songs was driven by their needs to the exposures of authentic and contextual English lexicons, the representations of learners' feelings and emotions through songs, the sense of enjoyable atmosphere songs created, and vocabulary retention. While listening to English songs, cognitive and metacognitive strategies were also applied by the participants to help them acquire vocabulary more effectively. At last, the study was concluded by proposing teachers' roles to enhance learners' autonomy in vocabulary learning through English songs.
\end{abstract}

Keywords: autonomy; autonomous learning; vocabulary learning; songs in L2 learning; learning strategies

\section{INTRODUCTION}

Vocabulary mastery plays an important role in the success of learners' learning. Learners who can show great vocabulary development tend to have less challenges in using the target language both in oral and written form. Nguyen and Nation (2011) highlighted the importance of vocabulary in foreign language learning. With adequate English vocabulary knowledge and development, effective communication, and interactions among people around the world can occur. Wilkins (in Xia, 2018) also argued that conveying meaning without vocabulary is impossible, while that without grammar can still be done. It indicated that the existence and mastery of vocabulary are aspects which everyone should achieve to be able to effectively use a language. In the context of foreign language learning, such as English in Indonesia, learners' ability to master a language - recognizing English words, knowing their meanings, and appropriately use the words in context - is inevitable yet challenging.

One problem found in Indonesia in relation to English language learning is regarding vocabulary. With the status of English as a foreign language, English teaching and learning process is limited in terms of the amount of time and input exposure. With the limited use of English in daily life, Indonesian learners may not be adequately exposed to the use of the language as well as its inputs which result in lack of vocabulary mastery and limited vocabulary size. If appropriate actions are not taken to deal with the issue on the lack of vocabulary mastery, it may be detrimental for Indonesian learners' English learning. Rahman, Yap, and Darmi (2018) emphasized how vocabulary size relates to English learning for bilingual students. In addition, Patahuddin, Syawal, and Bin-Tahir (2017) argued that vocabulary mastery played a pivotal role in language mastery: the more the vocabulary is mastered, the easier the language skills (i.e. reading, listening, speaking, and writing) can develop. To think 
in an opposite way, learners with limited English vocabulary may deal with difficulties which eventually will hamper their English mastery. In response to the problem mentioned above, learners' initiatives, and autonomy to gain supplementary learning sources and media to develop their English vocabulary is worth considering. With initiatives and autonomy, learners can be motivated to complement the missing or inadequate knowledge on the target language they are learning.

One learning medium learners can use to facilitate their English language learning is English songs. Through the use of songs in language learning, learners' initiatives and autonomy can be obtained as songs are nowadays an inseparable part of youth's lives. Songs can be used as an additional material or learning medium to expose learners to new linguistics knowledge, such as meanings of words, their forms, and context of the use (Romaniuk, 2019). Richards and Rodgers in Macancela, Valerina, Acosta, and Stagg (2016) also pointed out that songs can be used to enhance motivation, to promote learning acquisition, and to enhance listening skills and pronunciation. Through the depiction of real-life experiences and representations of emotions (Tomczak \& Lew, 2019) English songs offer to learners, songs enable learners to have long-lasting vocabulary mastery since the words they acquired through songs are contextual (Vishnevskaia \& Zhou, 2019). Tomczak \& Lew's study also revealed that contexts that songs' lyrics provide enable learners to have long-term memory to the acquired vocabulary.

Numerous studies on the incorporation of songs in ESL and EFL context in various countries have been conducted in the past decades. Experimental studies conducted in Persian (Javadi-Safa, 2018), Chinese (Luo, 2019), and Polish (Tomczak \& Lew, 2019) contexts showed the effectiveness of the use of songs for students' English learning. Besides different contexts, studies on different groups of participants were also carried out. The groups varied from young learners (Roohani \& Akbarpour, 2016; Y1lmaz, 2018), secondary school students (Borisai \& Dennis, 2016; Luo, 2019; Tomczak \& Lew, 2019), higher education students (Javadi-Safa, 2018), and Turkish' EFL teachers and primary elementary school students (Kömür, Saraç, \& Seker, 2011). The latter stressed the contribution of songs to vocabulary teaching and learning. In Indonesia, a study to investigate the effectiveness of songs in teaching speaking skills had been conducted by Wijaya (2018). The fourth semester Nursing students in English classes were grouped into a control group and an experimental one in which songs were used as a treatment. Data were collected through questionnaire, observation, testing, and documentation. The findings showed that the students in the experimental class achieved higher score than those in the control group. It indicated that songs were effective to be used as a medium to teach speaking skills.

Although numerous studies had been carried out, the authors identified some aspects which had not been investigated. While many studies focused on experimental design to see the effectiveness of songs, a qualitative one is noteworthy to be conducted in order to describe how learners, particularly those in EFL context, experienced vocabulary learning using songs. It will provide in-depth understanding on how songs help learners promote their language learning. Also, a study which pays attention to the experience of English department students may bring fruitful findings since English language learning is an inseparable part of their everyday lives and their needs which may lead to richer findings. Lastly, prior studies emphasized the use of songs in a classroom context, while some learners may also have experienced autonomy in vocabulary learning which also requires investigating. Considering the gaps, the present study was conducted to explore English department students' experiences in incorporating songs in their autonomous English vocabulary learning. The term 'autonomous' here reflected their own initiatives and practices in learning vocabulary outside in-class English instruction. The present study could fill up the gap of the prior studies; hence, the results of the study may shed new light and provide more understanding on the 
incorporation of songs in English learning, particularly how learners experienced vocabulary learning outside in-class English instruction.

\section{LITERATURE REVIEW}

\section{AUTONOMY IN L2 VOCABULARY LEARNING}

One important aspect of language which should be mastered to gain success in second or foreign language learning is vocabulary. Wilkins (in Xia, 2018) emphasized the importance of vocabulary mastery in that without the existence of grammar, one can still deliver messages; however, inexistence of vocabulary will result in total failure of message delivery. It indicated that having vocabulary mastery is pivotal in language learning. With the urgency of having vocabulary mastery as an indicator of success in English learning, the notion of L2 vocabulary learning autonomy offers a wider opportunity and support to gain learning goals. Learners' autonomy in vocabulary learning is imperative as the extent of success or failure of their lexical growth lies in learners' hand (Kaur, 2013). Kaur further added that learners own the responsibility for the vocabulary acquisition and its development as well as creating opportunities for vocabulary learning to occur. Nation in Kaur (2013) argued that autonomy can be gained when some conditions are met. They need to be able to set priorities on what aspects to focus on, what to review, how to process materials, and how teacher - students interaction is carried out. Learners' ability to fulfil these conditions may lead to students' autonomy in learning.

\section{STRATEGIES IN LISTENING SKILLS}

Various definitions have been proposed by many scholars to provide better understanding on what a learning strategy is. Different keywords such as actions learners do (Oxford, 1990), techniques learners employ (Gu \& Johnson, 1996), and special behaviours an individual shows (O’Malley, Chamot \& Küpper, 1989) were proposed to help understand learning strategies. The present study operationally defined learning strategies as any actions and activities taken by learners to make their learning easier, more successful, enjoyable, and autonomous. Gu and Johnson (1996) argued that employing strategies suitable for vocabulary learning and retention will be beneficial for language learning.

In enhancing listening skills, learners are required to employ suitable learning strategies which enable them to make learning more successful and enjoyable. O'Malley et al. (1989) categorized learning strategies into three different divisions: cognitive strategies, metacognitive strategies, and social/affective strategies. Cognitive strategies deal with mental processes a learner should undergo to accomplish a task or a goal. The strategies can include main idea identification, inferencing, predicting, notetaking, information elaboration, imaging, translating, and summarizing. The second category, metacognitive strategies have something to do with learners' ability to regulate their learning. Metacognitive strategies involve planning, monitoring, and evaluation on the learning process an individual goes through. The last category is social/affective strategies. Learners who employ social/affective strategies tend to express the needs of interaction and collaboration during learning process as well as control over affective factors, for instance lowering anxiety level, which may influence their learning.

\section{VOCABULARY LEARNING THROUGH SONGS}

Songs are beneficial to be used in language learning. They can promote foreign language learning as they provide linguistic aspects such as vocabulary, grammar, and pronunciation. 
Interestingly, those linguistic aspects are commonly acquired incidentally as they enjoy listening to songs for fun rather than for learning intentionally (Vishnevskaia, \& Zhou, 2019). Therefore, music and songs can lead to a non-threatening and fun learning atmosphere resulting in learners' emotional, social, and academic development (Paquette \& Rieg, 2008). Through gradual processes of listening to a song, learners will eventually show emotional attributes to the song. This psychological aspect will result in a long-term retention on the words used in the songs (Javadi-Safa, 2018). Learners can also develop their listening comprehension, vocabulary acquisition, pronunciation, and cultural understanding of the target language and make the learning be more contextual and authentic leading to a real-life use of the target language as well as raising their linguistics awareness (Macancela et al., 2016).

\section{AFFECTIVE FILTER HYPOTHESIS}

Krashen (1982) explained that Affective Filter Hypothesis emphasized how affective attributes such as motivation, self-confidence, and anxiety relate to the success of second language acquisition. Motivation and self-confidence serve as variables which facilitate learning, while the latter, anxiety may tend to hamper learning and acquisition. No matter how rich the input a learner is exposed to, if the affective filter he has is high, language acquisition will be blocked. Krashen further suggested that in relation to pedagogical matter, creating a low affective filter atmosphere is as important as providing comprehensible input. Learning, as an instance, should be performed in a low anxiety situation. Xu (2016) also pointed out that in language learning, the extent of learners' affection filter should be reduced to allow more input to be acquired.

\section{RESEARCH METHOD}

\section{DESIGN}

The study was aimed at exploring four learners' experiences in incorporating songs into their autonomous English vocabulary learning. Descriptive qualitative design was applied in the study since it explored an individual's opinions, perceptions, and experiences (Creswell, 2002). Meanwhile, Merriam (1998) asserted that within descriptive design, detailed depiction of people or groups of people's experiences on a particular event can be gained. Therefore, through descriptive qualitative method, participants' experiences, and opinions towards the use of songs to support their autonomous vocabulary learning can be comprehensively elaborated.

\section{PARTICIPANTS}

The study involved four sophomores taking English Study Program in a university in Yogyakarta, Indonesia. The four participants were selected to participate in the present study due to their experiences in using songs to learn vocabulary outside the English teaching and learning process in the classroom. Through prior interview, the authors ensured that the candidates intentionally listened to English songs as a medium they used to learn vocabulary. In other words, these four students applied autonomous vocabulary learning through songs. They also expressed willingness to be participants of the present study. The four participants were all female and addressed as Joanna, Suzy, Alice, and Mia (pseudonyms) in the findings section.

\section{DATA COLLECTION METHOD}

To collect the data, in-depth interview was carried out to the four participants. In-depth interview was suitable for the study since both participants and researchers can dig out real-life 
experiences as well as point of views of a matter (Cohen, Manion \& Morrison, 2011). The interview was aided by an interview protocol which covered general questions related to the implementation of songs in the participants' autonomous English vocabulary learning. Although an interview protocol was used, unstructured responses were applied to allow the participants to express any feelings, opinions, situations, or specific actions they had related to their experiences in learning vocabulary through English songs.

The data were obtained through some steps. At first, one of the authors conducted a prior interview to find candidates who met the criteria of the participants in the study. After finding the suitable participants, a consent to participate in the study was asked to each participant to ensure there would be no conflict of interests in the future. Once the participants consented to be interviewed, the one-on-one in-depth interview was carried out by one of the authors. To avoid misunderstanding and language barriers, the interview was conducted in Indonesian language which is the first language of both the authors and the participants.

\section{DATA ANALYSIS}

The interview was transcribed verbatim as an initial step of data analysing process. The transcripts of the interview were then coded by the second author to find the themes based on the obtained data. Cohen et al (2011) explained that coding process is gone through to label data based on pre-determined themes or emergent ones. In the present study, coding was done based on themes emerged in the interview. To maintain trustworthiness of the findings, member checking was administered by reporting the results of the coding to the participant to see whether objection was issued, or changes should be made. The results of the member checking showed that the participants agreed on the coding results. The coding results were then finalized by the first authors without changing the essence of data obtained from the participants.

\section{RESULTS AND DISCUSSION}

The in-depth interview conducted to the participants revealed three main themes related to the experiences they had in incorporating songs into their autonomous English vocabulary learning. The three themes were preferred tempo of selected songs, the reasons of using songs in vocabulary learning, and the strategies they employed in learning vocabulary through English songs. The findings of each theme are explained in the following section.

\section{PREFERRED TEMPO}

In the interview, the participants reported that they liked a specific music tempo they usually used in learning vocabulary. Joanna said "I preferred more melodramatic songs. Melodramatic songs tend to have slow beat, so the words used in the songs are clear and I can understand better. So, I can also learn how to pronounce the words". Alice and Mia had the same idea on the kind of songs they used to enrich their vocabulary.

"I preferred an easy listening song for my learning, especially the one which has slow beat and is melodramatic. I also love songs which represent my feelings, so it can raise my curiosity to know more about the meanings of the words" (Alice).

Mia also expressed her preference on slow beat music over a fast one as a medium for her vocabulary learning.

"I like slow beat songs. I don't like the fast ones especially when there is a rap part with which I cannot keep up with the words mentioned by the singers. While in a slow beat song, I can understand the pronunciation more easily" (Mia). 
The findings showed that slow beat songs were preferred by the participants to use in their autonomous English vocabulary learning. It is understandable that they selected slow beat songs over fast beat ones as in slow beat songs, the words and how they are pronounced can be clearly and easily followed by the students. These findings resonated that of Macancela et al. (2016) who found that 58\% of the respondents of their study preferred romantic songs over rock, metal, and other genres. Romantic songs usually have slow beat; therefore, they are easily followed by learners to support their learning. Sohot and Yunus's (2019) findings also highlighted the importance of careful selection of songs to support learning. The findings suggested that the selected songs should be simple, and their lyrics should be easily comprehended by learners. Another important aspect which should be highlighted from the findings are in terms of the participants' ability to identify and select the kinds of songs which meet their learning needs. In the context of the present study which focused on autonomous vocabulary learning, students' preference in songs they used in their learning played a crucial role. As the learning was done autonomously, the learners might get minor assistance for others; therefore, selecting appropriate songs for them, for instance the ones they liked, may help them sustain their learning. Learners who can identify and select songs which meet their learning needs will result in motivation in learning (Macancela et al., 2016).

\section{REASONS OF INCORPORATING SONGS}

From the interview, four reasons of incorporating songs in vocabulary learning among the participants emerged. The reasons were exposure to authentic English words, representations of learners' feelings and emotions, fun way of learning, and vocabulary retention.

\section{EXPOSURE TO AUTHENTIC ENGLISH WORDS}

In the interview conducted to Joanna, she pointed out the reasons of using songs to support her autonomous vocabulary learning. She said that she chose to learn vocabulary through songs because she could model pronunciation native speakers (the singers) said to the lyrics of the song as well as the dictions they used. "There are many words mentioned by the singers who are native speakers, so it can add my knowledge on how to pronounce words correctly" (Joanna). She further added "I also learnt the words they chose to express themselves". In relation to dictions, Suzy also emphasized the possible exposure of different varieties of English when learning English vocabulary through English songs. She said "The way I see it, English songs are not all the same in that there are many varieties in English, like American English, British English, and others. From the different songs, I can learn various vocabulary".

The excerpts showed that the incorporation of songs in the participants' autonomous English vocabulary learning enabled them to be exposed to authentic target language used by native speakers. They can learn how a word is pronounced by native speakers or the singer and eventually they imitate it and enhance their pronunciation. Learners can benefit from the incorporation of songs in their learning as it will be more contextual and authentic leading to a real-life use of the target language as well as raising their linguistics awareness (Macancela et al., 2016). In addition, with the ample exposure of different varieties of English, learners are also unintentionally introduced to the culture of the target language. Not only one specific kind of English, through English songs, learners can also be exposed to various dictions used in different English-speaking countries (Macancela et al., 2016).

REPRESENTATIONS OF LEARNERS' FEELINGS AND EMOTIONS

Another reason of using songs in the participants' autonomous vocabulary learning was related to emotional attributes. Joanna claimed that she was interested in using songs as a medium for 
her vocabulary learning since English songs somehow can resonate her feelings and emotions. "Songs are a universal language. Sometimes I can feel the song and it seems like the songs and I are united. The lyrics reflect my feelings, so I feel like learning new words which represent myself" (Joanna). She also added "I can feel the songs, and indirectly I acquire new words from the songs". Joanna indicated that of various ways to support her autonomous vocabulary learning, songs were the preferred one since they have the ability to reflect her feelings. Vishnevskaia and Zhou (2019) pointed out that young people can benefit from the use of English popular songs in their English learning as they can be associated with their lives, interests, feelings, and experiences. This resemblance may eventually motivate them in learning.

These findings can also be analysed with Affective Filter Hypothesis. This hypothesis proposed that learners' affective variables such as motivation, self-confidence, and anxiety influence their success in second language acquisition (Krashen, 1982). Learning through songs can reduce learners' anxiety level as the nature of songs is relaxing and it can create a non-threatening environment when used as a tool in learning. When learners are less anxious and more motivated, the vocabulary acquisition can possibly occur. Besides enhancing motivation and lowering anxiety in learning, songs can also result in long-term retention on the newly acquired words. Through gradual process of listening to a song, learners will eventually show a sense of emotional attributes to the song. This psychological aspect will result in a longterm retention on the words used in the songs. Besides psychological attribute, learners will acquire new vocabulary when it is of their needs (Javadi-Safa, 2018).

\section{FUN WAY OF LEARNING}

When explaining the reasons why they selected songs to facilitate them to learn vocabulary autonomously, Alice and Suzy provided a comparison on how listening to English songs brought different effects compared to reading books. Alice stated "listening to songs is enjoyable while reading books is not. I am not into reading, so I prefer listening to English songs to reading books. I think acquiring new vocabulary through songs is more fun and relaxing." In addition, Suzy also said "to learn vocabulary, it is easier when I use songs because it is fun and less boring. It is different from learning from books which tends to be boring". It is interesting to note that the sources of input - listening to songs and reading books - Alice and Suzy raised were all receptive skills. It indicated that the participants were aware of the sources of input exposure they could use; however, they selected listening to English songs as a medium for them to learn vocabulary. Music and songs can lead to a non-threatening and fun learning atmosphere resulting in learners' emotional, social, and academic development (Paquette \& Rieg, 2008).

In a similar vein, Suzy also expressed their preference to use English songs in her English vocabulary learning due to its possibility to create an incidental learning.

\footnotetext{
"[when learning using English songs] I don't feel like learning, and it is good. When I intentionally learn something, sometimes I find it difficult to acquire and memorize new words. With music, which is repeated over and over, I can recognize words and find their meaning" (Suzy).
}

The excerpt showed that learning through songs can lead to subconscious learning and vocabulary acquisition. Students do not realize that they are learning something, so it reduces the burden they may feel. Vishnevskaia and Zhou (2019) stressed that songs are beneficial to promote foreign language learning as they provide linguistic aspects such as vocabulary, grammar, and pronunciation. Interestingly, those linguistics aspects are commonly acquired incidentally as they enjoy listening to songs for fun rather than for learning intentionally. Not only helping learners acquire new vocabulary, learning through songs also indirectly rehearse 
their newly learnt vocabulary while they are listening to the songs. Songs usually use repetitive words and expressions which enable learners to practice new words and their structure (Tomczak \& Lew, 2019). This finding resonates Borisai and Dennis' (2016) findings with Thai students which showed that the students who learnt through pop songs were more motivated in learning vocabulary as they learnt vocabulary in a relaxing and fun atmosphere.

VOCABULARY RETENTION

The last reason of incorporating songs in autonomous vocabulary learning emerged in the interview was for vocabulary retention. Mia reported,

\footnotetext{
"It is nice to use songs in my learning as I will gain long-lasting memory on the new words I learnt. It is different from intentional memorizing process like the one I had in class which commonly led to easily forgotten words. When I put the new word in songs, I can easily remember the words" (Mia)
}

The finding showed that words acquired by the participants when she was using songs for her vocabulary learning resulted in long-term memory. It is in line with Javadi-Safa (2018) who stated that vocabulary learners acquired through songs will be long-lasting. Other studies also reported that one of the impacts of songs in English learning was in term of vocabulary retention. Through songs, students can remember and memorize words used in the songs (Shakerian, Rezaei, Murnani, \& Moeinmanesh, 2016; Demirci, \& Yavaslar, 2018) , even knowing the meaning of new words they acquired without looking up dictionary or asking other people (Shakerian, et.al, 2016).One possible reason on the long-term memory to possibly occur when learners incorporate songs in their learning is since songs are repetitive in nature (Javadi-Safa, 2018).

\section{STRATEGIES EMPLOYED WHILE LISTENING TO SONGS}

The participants reported using four different strategies when they autonomously learnt vocabulary using songs. The first strategy was notetaking. Joanna said that "I mostly use notetaking when listening songs". She also told that she got used to doing notetaking since she was in secondary school.

\footnotetext{
"I actually had a book on which all words I obtained from songs were written. When I was in secondary schools, I loved jotting down new vocabulary I got. When I had spare time, I reopened the books and reviewed the words I acquired back then" (Joanna).
}

Notetaking strategy was also employed by Suzy when she was listening to English songs. She also stated "Usually, when I find difficult or unfamiliar vocabulary, I will take notes on notebooks and write the meanings". The second strategy emerged was imaging strategy. When acquiring new vocabulary, Joanna said "I put the words I jot down on the wall". The same strategy was also employed by Suzy. "Sometimes, I made a mini whiteboard at home and I wrote words I got from English songs I listened to. So, when I was listening to the songs again, I could check the words and how they were pronounced" (Suzy). The last strategy emerged in the interview was predicting strategy. Mia asserted "[While listening to a song] I usually looked at the lyrics to make sure the words I predicted were correct or not. I am happy when I can correctly predict the words. By predicting, I can easily memorize the words". Alice also employed the same strategy. She stated "At first, I usually listen to the songs without lyrics and I write the words I hear and the pronunciation. Afterwards, I check the lyrics".

Songs can be an effective medium for learning as the lyrics are usually used in context and their melody makes it easier for learners to memorize new words they acquire in the lyrics of the songs (Javadi-Safa, 2018). It finally eases learners to remember and understand the new words they acquired. The excerpts also showed that the participants employed various 
strategies while learning vocabulary using songs. In Joanna and Suzy's cases, notetaking was commonly applied when they acquired new vocabulary by which they also wrote the meanings. Notetaking is a strategy which includes into cognitive strategies (O'Malley et al., 1989). While listening to the songs and understanding the words used in the songs, they actively process the information in the brain. This mental process marks the cognitive strategies they employed. Another activity included into cognitive strategies also emerged. Mia and Alice indicated that they predicted words used in the songs, either their form or their pronunciation. Predicting is one strategy under cognitive strategies O'Malley et al. (1989) proposed. In predicting, learners can anticipate the contents of a text they are reading or listening. In this case, when they predicted what comes next in the lyrics, it indicated that mental processes to understand the overall picture of the text occurred. Besides cognitive strategies, Joanna and Suzy also showed that they employed metacognitive strategies. The fact that they organized their vocabulary learning by writing new words they acquired indicated that they had some planning for their learning. Also, they self-monitored their learning by checking out word lists they made to review and refresh their knowledge. Oxford (1990) explained that when learners organized their learning through planning, monitoring, and evaluation, they employ metacognitive strategies - strategies learners commonly use to regulate their learning.

The employment of cognitive and metacognitive strategies among the participants showed that they made some efforts to help them succeed in their learning. Rather than simply listening to English songs for fun, they applied some strategies to develop their vocabulary. It echoed Macancela et al. (2016) who asserted that incorporation of songs in language learning should be accompanied by appropriate and suitable learning strategies and techniques to achieve a fun learning atmosphere. Despite the activities they did while listening to English songs as a medium for their autonomous English vocabulary learning, their decision to use songs in their learning itself indicated affective strategies they preferred. They loved the idea of incidental and fun learning which deals with psychological aspects which contributed to the decision of using songs for their vocabulary learning.

\section{CONCLUSION}

The study showed that slow beat songs were more preferred to use in vocabulary learning. With the nature of learners who need guidance and have different pace which suit their learning, slow beat songs enable them to follow the lyrics and comprehend the words used in the lyrics. Learners who are interested in developing their vocabulary knowledge may also make use of English songs particularly slow beat ones which suit their proficiency, preference, pace, and needs. Although the context of this study was in learners' autonomy which might not stress teachers' involvement in students' learning, providing guidance on the kinds of music students can select is still noteworthy. Teachers play a crucial role in selecting suitable songs to support students' learning. Teachers' competence to assist students to make use of available technology, such as songs may help them become more autonomous and be able to regulate their own learning and achieve their goals (Rahmawati, 2019). The lyrics of the songs should be comprehensible, subject-related, and repetitive as well as having a sense of raising students' involvement in meaning discovery (Sohot \& Yunus, 2019). Besides in the realm of songs selection, teachers' assistance can also include the exposure of different kinds of strategies learners can employ while incorporating songs in their vocabulary learning autonomy. However, the decisions on what strategies to apply in the vocabulary learning are still in learners' hands. Learners are free to apply strategies which they believe to match their learning needs. 


\section{REFERENCES}

Borisai, T., \& Dennis, N. K. (2016). A study of using pop songs to promote new vocabulary learning for secondary school students. International Journal of Research, 4(1), 86-92.

Cohen, L., Manion, L., \& Morrison, K. (2011). Research Methods in Education. $7^{\text {th }}$ Ed. London: Routledge.

Creswell, J. W. (2002). Educational Research: Planning, Conducting, and Evaluating Quantitative. Upper Saddle River, NJ: Prentice Hall.

Demirci, C., \& Yavaslar, E. (2018). Active learning: Let's make them a song. Cypriot Journal of Educational Sciences, 13(3), 288-298.

Fitria Rahmawati (2019). Blended learning in an English listening and speaking course: Freshmen's voice and choice. Paper presented at The Third International Conference on Sustainable Innovation 2019 Humanity, Education and Social Sciences (ICOHESS 2019). Indonesia: Universitas Muhammadiyah Yogyakarta, July.

Gu, Y., \& Johnson, R. K. (1996). Vocabulary learning strategies and language learning outcomes. Language Learning, 46(4), 643-679.

Javadi-Safa, A. (2018). Effects of using songs on adult EFL learners' vocabulary learning. Journal of Applied Linguistics and Language Research, 5(3), 101-112.

Kaur, N. (2013). The need for autonomous vocabulary learners in the Malaysian ESL classroom. GEMA Online ${ }^{\circledR}$ Journal of Language Studies, 13(3). 7-16

Kömür, Ş., Saraç, G., \& Şeker, H. (2011). Teaching English through songs (Practice in Muğla/Turkey). Sosyal ve Beşeri Bilimler Araştirmalari Dergisi, 1(15). 109-120

Krashen, S. (1982). Principles and Practice in Second Language Acquisition. Retrieved January 27, 2020 from Https://Www.Semanticscholar.Org/Paper/Principles-And-Practice-In-Second-LanguageKrashen/4b85d72a8edbd47b4ba3e0b563f1563f6e9f746b\#References

Luo, S. (2019). Influence of singing English songs on vocabulary learning by senior school students In Guangzhou. International Journal of Information and Education Technology, 9(11). 843-848.

Macancela, I. J. M., Valerina, B., Acosta, L., \& Stagg, G. I. (2016). Applying English songs and their effects on English language learning. Revista Científica Ciencia Y Tecnología, 2(10). 17-25.

Merriam, S. B. (1998). Qualitative Research and Case Study Applications in Education. Revised and Expanded from" Case Study Research in Education.". San Fransisco: Jossey-Bass Publishers.

Min Xu. (2016). The application of Input Hypothesis and Affective Filter Hypothesis in colleges English listening teaching. Paper presented at The 2016 2nd International Conference on Education Technology, Management and Humanities Science (ETMHS 2016). China, January

Nguyen, L. T. C, \& Nation, P. (2011). A bilingual vocabulary size test of English for Vietnamese learners. RELC Journal, 42(1), 86-99.

O'Malley, J. M., Chamot, A. U., \& Küpper, L. (1989). Listening comprehension strategies in second language acquisition. Applied Linguistics, 10(4), 418-437.

Oxford, R. (1990). Language Learning Strategies. In Anne Burns and Jack C. Richards (Eds.). The Cambridge Guide to Learning English as a Second Language. Cambridge: Cambridge University Press.

Patahuddin, P., Syawal, S., \& Bin-Tahir, S. Z. (2017). Investigating Indonesian EFL learners' learning and acquiring English vocabulary. International Journal of English Linguistics, 7(4), 128-137. http://doi.org/10.5539/ijel.v7n4p128

Paquette, K. R., \& Rieg, S. A. (2008). Using music to support the literacy development of young English language learners. Early Childhood Education Journal, 36(3), 227-232.

Rahman, A., Yap, N. T., \& Darmi, R. (2018). The association between vocabulary size and language dominance of bilingual Malay-English undergraduates. 3L: Language, Linguistics, Literature ${ }^{\circledR}, 24(4), 85-101$. http://doi.org/10.17576/3L-2018-2404-07

Romaniuk, S. (2019). Learning English through songs as one of innovative methods of education. Інноватика У Вихованні, 9, 225-229. https://doi.org/10.35619/iiu.v0i9.12

Roohani, A., \& Akbarpour, S. (2016). The effect of using songs on young Iranian EFL learners' vocabulary learning: A case of gender. Journal of Modern Research in English Language Studies, 3(3), 82-59.

Shakerian, P., Rezaei, O., Murnani, Z. T., \& Moeinmanesh, H. (2016). Investigating the role of pop songs on vocabulary recall, attitude, and retention of Iranian EFL learners: The case of gender. Advances in Language and Literary Studies, 7(2), 121-128. http://dx.doi.org/10.7575/aiac.alls.v.7n.2p.121

Sohot, M. B., \& Yunus, M. M. (2019). Pupils' perceptions on the use of action songs in teaching and learning vocabulary. International Journal of Innovative Research and Creative Technology, 4(6), 117-120.

Tomczak, E., \& Lew, R. (2019). "The song of words": Teaching multi-word units with songs. 3L: Language, Linguistics, Literature ${ }^{\circledR}, 25(4)$. 16-33.

Vishnevskaia, M., \& Zhou, Z. (2019). The impact of using music and songs on teaching EFL in China by nonnative English teachers. Universal Journal of Educational Research, 7(8), 1808-1813. 
Wijaya, T. W. (2018). The effectiveness of songs for teaching speaking. Journal of Foreign Language Teaching and Learning, 3(2), 74-85. https://Doi.Org/10.18196/Ftl.3231

Xia, X. (2018). An effective way to memorize new words-lexical chunk. Theory and Practice in Language Studies, 8(11), 1494-1498.

Y1lmaz, D. (2018). The effectiveness of using songs in teaching vocabulary to very young learners in a foreign language teaching classroom. Unpublished MA thesis, Çă̆ Üniversitesi Sosyal Bilimler Enstitüsü, Turkey. 